\title{
Application of "green design" sustainable concept in transmission line
}

\author{
De Guang Zhang ${ }^{1}$, Ya Ning Ren ${ }^{1}$, Fan Gao ${ }^{1}$, Li Huan Wang ${ }^{1}$, Zhe Liu $^{2}$ \\ ${ }^{1}$ State Grid Hebei Economic Research Institute, Shijiazhuang City, Hebei Province \\ ${ }^{2}$ State Grid Hebei Electric Power Co., Ltd, Shijiazhuang City, Hebei Province
}

\begin{abstract}
According to the requirements of sustainable development, through scientific planning of engineering design activities, the sustainable concept of "green design" is introduced into the design of transmission line. The green design method is elaborated in four aspects: electrical design of transmission line, design of tower foundation, structural design of tower body and cable design, which guide the "green construction" of saving resources, protecting environment, improving efficiency and ensuring quality, so as to achieve the goal of saving resources and reducing the negative impact on the environment to the maximum extent. Therefore, the sustainable concept of "green design" has far-reaching promotion significance and prospects.
\end{abstract}

\section{INTRODUCTION}

With the rapid development of modern society and economy, the rapid increase of productivity, the excessive consumption of resources and the increasing deterioration of the environment have attracted extensive attention of the society. In the context of environmental issues, the concept of "green design" came into being. Green design is a design concept and method for the purpose of saving resources and protecting the environment. It emphasizes the protection of natural ecology and the full use of resources.

The sustainable concept of "green design" is introduced into the design of transmission line [1]. This paper expounds the application of "green design" in the transmission line industry from four aspects of line electrical design, which are electrical design of transmission line, design of tower foundation, structural design of tower body and cable design. The green design of transmission line not only further promotes the highquality construction of power transmission and transformation projects, but also effectively realizes the purpose of saving resources and protecting the environment.

\section{ELECTRICAL DESIGN}

\subsection{Path choice}

The route selection of the line should comprehensively consider the power grid planning, urban planning, environmental protection, line length, meteorological conditions, topography, traffic conditions, construction and operation and other factors, and make multi scheme technical and economic comparison to ensure safe and reliable, environment-friendly, economic and reasonable, convenient and mechanized construction [2].

The route selection should adopt three-dimensional digital map, satellite image and other technologies [3]. Through the image map, the route selection can ensure the feasibility of the route, and take into account that the tower does not occupy or less cultivated land and the land with high economic benefits, so as to achieve the purpose of maximum land saving and rational use of land.

In order to protect the soil and water conservation function of the existing land and vegetation to the maximum extent, the path should avoid the virgin forest, nature reserves and scenic spots, ecologically fragile areas, key soil and water loss prevention and protection areas and key control achievement areas designated by the state.

The path should avoid forest area and cash crop area as far as possible. When avoiding difficulties, high span plan should be adopted to avoid or reduce the felling of forest area to the maximum extent.

The route should avoid passing through the densely populated area of residential buildings as far as possible to avoid the demolition of a large number of residential buildings. The tower foundation does not occupy or less grassland, cultivated land and land with high economic benefits, so as to prevent soil erosion and land desertification.

The route selection should be parallel to the existing lines as far as possible, the distance between them should be controlled to the minimum, and a high-voltage line corridor should be shared to improve the utilization rate of the line corridor. 
The route selection shall meet the requirements of electromagnetic impact on shortwave radio reception station, medium wave navigation station, air intelligence radar station, TV relay station, AM radio station and other radio stations, weak current lines and other facilities [4].

In the preliminary design and construction drawing design stage, three-dimensional design technology should be actively used. Combined with aerial photography [5], the geographic information system of route corridor is established, and the crossing model is built. This is conducive to the reasonable optimization of the path and avoiding the current obstacles [6].

At the same time, it is necessary to carry out multi scheme route selection and route scheme comparison to reduce the length of route and the number of corners as much as possible. Furthermore, the path tortuosity coefficient should be reduced as far as possible, and the proportion of tension tower should be reduced to ensure the reasonable comprehensive index.

\subsection{Transmission line corridor}

In order to improve the transmission capacity per unit corridor width and the utilization rate of land resources, the multi circuit technology on the same tower should be actively adopted, and the conductor cross section should be selected reasonably in combination with power grid planning, load growth and other factors.

The V-shaped insulator string, vertical arrangement of conductors and other tower types occupying narrow corridor should be adopted in the crowded corridor, so as to reduce the width of line corridor

\subsection{Selection of conductor and ground wire}

Combined with the actual situation of the project, according to the conductor selection, conductor section, splitting type, project cost and other aspects of comprehensive comparison and selection, actively promote the application of energy-saving conductor. If conditions permit, OPGW composite optical cable shall be used for both ground wires as far as possible.

For multi circuit AC transmission lines on the same tower, the phase sequence arrangement of conductors should be optimized to improve the line operation reliability, so as to reduce the power loss caused by the imbalance between circuits and improve the power quality. At the same time, the outer diameter of conductor, and the arrangement of sub conductor with phase conductor should be reasonably selected to reduce the surface field strength of conductor and reduce the radio interference and audible noise.

The ground wire of $220 \mathrm{kV}$ and above transmission lines should adopt the operation mode of sectional insulation and one point grounding [7], which can effectively reduce the power loss. When the transmission line is long, complete transposition measures should be taken to reduce power loss.

\subsection{Fittings and insulators}

The new transmission lines should adopt fittings made of non ferromagnetic materials to reduce hysteresis and eddy current losses. At the same time, energy-saving fittings should be actively used [8], such as aluminum alloy energy-saving suspension clamp, new anti running, anti-wear and anti vibration hammer (as is shown in Fig. $1)$, etc.

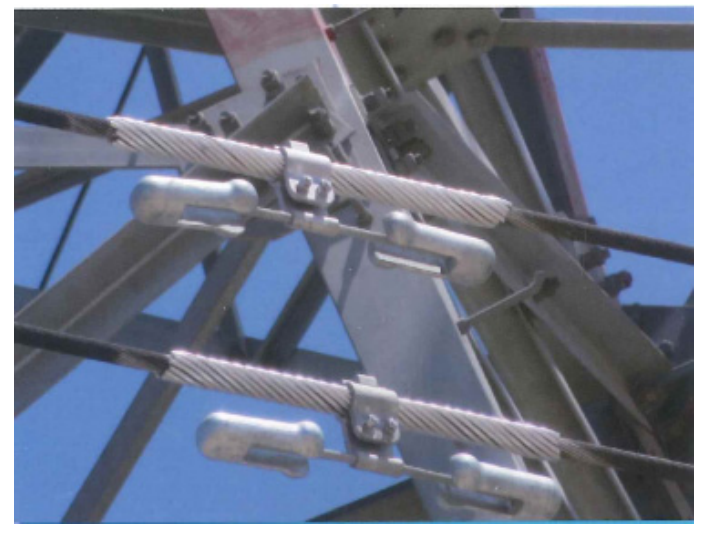

Fig. 1 new anti running, anti-wear and anti vibration hammer

According to the local natural conditions and environmental characteristics of the line, the division of pollution areas should be determined, the insulation level of the line should be reasonably configured, and the type selection of insulators should be matched. Corresponding bird prevention facilities shall be designed according to bird damage along the line to reduce tripping accidents caused by bird damage. Effective anti galloping measures should be taken in galloping areas above grade 0 of transmission lines.

\subsection{Insulation lightning protection and lightning protection grounding}

The lightning protection design of transmission line should be based on line voltage, load nature and system operation mode. Combined with the operation experience of local existing lines, the intensity of regional lightning activity, the characteristics of topography and low soil resistivity, after calculating the lightning withstand level, the reasonable lightning protection method is adopted through technical and economic comparison.

The grounding body of the transmission line located in the cultivated area should be buried below the cultivated depth. The grounding body of transmission line in residential area and paddy field shall be laid in a ring.

\section{DESIGN OF TOWER FOUNDATION}

Combined with the actual situation of the project, make full use of the nearby provincial roads and township roads and reasonably plan the construction access roads according to the principle of combining permanent roads with temporary roads[9].If implemented in this way, it can effectively reduce the unit line construction cycle, reduce the occupation of land, minimize the 
transportation cost, save manpower and reduce the transportation period.

According to the characteristics of topography and geology, the foundation type should be selected reasonably, and the foundation type with undisturbed soil bearing capacity should be used preferentially. The design of foundation depth, chassis width and diameter is optimized to make full use of the bearing capacity of foundation soil. In this way, undisturbed soil foundation can effectively reduce the use of materials compared with large excavation foundation. Taking DongyangChengdong $110 \mathrm{kV}$ transmission line project as an example, N15 tower is selected, and the tower type is 1D5-SJ2-18. Then, the calculation is carried out with cast-in-place pile foundation and large excavation foundation, and the specific material consumption is shown in Table 1 below.

Table 1 Comparison of two types of foundation

\begin{tabular}{|c|c|c|c|c|c|c|}
\hline $\begin{array}{c}\text { Tower } \\
\text { Numb-er }\end{array}$ & $\begin{array}{c}\text { Founda-tion } \\
\text { type }\end{array}$ & \multicolumn{2}{|c|}{ Size } & $\begin{array}{l}\text { Quanti-ty of } \\
\text { concrete }\end{array}$ & $\begin{array}{l}\text { Quanti-ty of } \\
\text { reinforcement }\end{array}$ & $\begin{array}{c}\text { manufac-turing } \\
\text { cost }\end{array}$ \\
\hline \multirow{4}{*}{ N15 } & Large & Buried depth & $3.8 \mathrm{~m}$ & \multirow{2}{*}{$46.39 / \mathrm{m}^{3}$} & \multirow{2}{*}{$2.37 / \mathrm{t}$} & \multirow{2}{*}{$\begin{array}{l}92800 \\
\text { yuan }\end{array}$} \\
\hline & $\begin{array}{l}\text { Excava-tion } \\
\text { Founda-tion }\end{array}$ & Lengthxwidth & $4.0 \mathrm{mx} 4.0 \mathrm{~m}$ & & & \\
\hline & Cast in & Pile diamet-er & $1 \mathrm{~m}$ & \multirow{2}{*}{$26.71 / \mathrm{m}^{3}$} & \multirow{2}{*}{$1.76 / \mathrm{t}$} & \multirow{2}{*}{$\begin{array}{l}56700 \\
\text { yuan }\end{array}$} \\
\hline & founda-tion & Pile length & $8.5 \mathrm{~m}$ & & & \\
\hline
\end{tabular}

It can be seen from the above table that the concrete volume of undisturbed soil foundation (cast-in-place pile foundation) is reduced by $19.68 \mathrm{~m} 3$, about $42.42 \%$ compared with large excavation foundation. Compared with the large excavation foundation, the reinforcement amount of undisturbed soil foundation (cast-in-place pile foundation) is reduced by 0.61 tons, about $25.74 \%$.

In addition, compared with the large excavation foundation, the total cost of undisturbed soil foundation (cast-in-place pile foundation) is reduced by 36100 yuan, about $38.90 \%$, as shown in Fig. 2 .

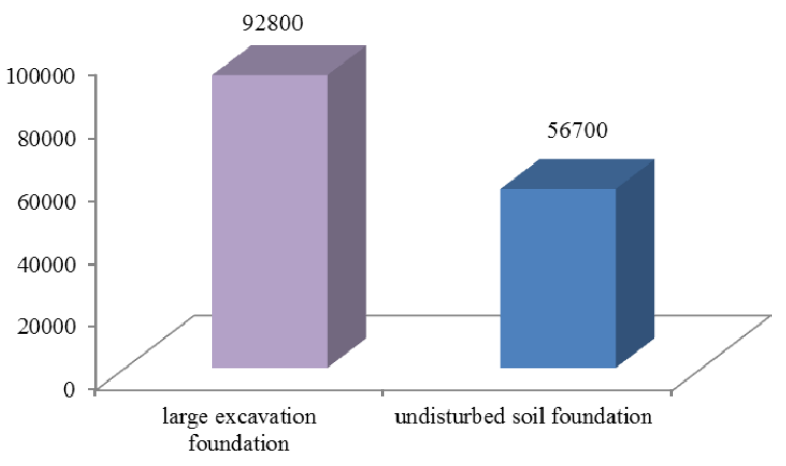

Fig. 2 Cost comparison between undisturbed soil foundation and large excavation foundation

When large excavation foundation is selected due to geological conditions and surrounding environmental factors, flexible foundation should be selected instead of rigid foundation to reduce concrete volume. Effective measures should be taken to restore the natural appearance after the completion of large excavation foundation construction, so as to minimize the impact of the project on the environment.

The cast-in-place pile foundation is preferly adopted under the special engineering conditions of large load, low foundation bearing capacity and shallow groundwater level. In this case, land occupation and earthwork excavation are reduced.

Long-short leg design should be actively adopted for transmission towers in mountainous areas, which can adapt to various complex terrain. According to local conditions, the long-short legs are combined with the high and low foundation of undisturbed soil, and the reasonable residual soil treatment measures are set, which can successfully achieve zero base level[10]. This measure can effectively reduce the amount of earth rock excavation and soil erosion, and protect the natural ecological environment to the greatest extent. Retaining and drainage facilities shall be set before excavation in rain washed area. On the premise that the rock is complete and firm, the advanced technologies such as rock bolt and rock bottom expanding anchor pile can be adopted after special topic demonstration, which can effectively reduce the consumption of reinforced concrete and steel materials.

In the engineering design stage, reasonably determine the concrete strength grade and protective layer thickness, according to the engineering environment, geological corrosion and other conditions. Commercial concrete and centralized mixing concrete are preferred for foundation concrete pouring to minimize environmental pollution. In addition, HRB400 grade reinforcement is used as the main reinforcement of tower foundation reinforcement. Compared with other grades of reinforcement, it can not only meet the strength requirements, but also save steel consumption.

\section{StRUCTURAL DESign OF TOWER BODY}

For transmission line with tight land use for tower sites in urban and suburban areas, steel pipe poles, steel pipe towers and narrow foundation towers should be used to reduce land occupation.

According to the mechanical characteristics of the tower, reasonable tower material, component section and bolt grade are adopted to achieve the best economic benefits. For the tower with large load, Q420 and above high-strength steel is actively used for the main pipe (or main material), and large-size angle steel above L200 can be used for the section, so as to further reduce the steel consumption of the tower. 
After the external load of tower structure is determined, the tower head layout, tower body slope, main material section, web member layout, cross section layout, member section form and steel material should be optimized. In order to make full use of the main material stress and save the gusset plate material, the arrangement of main material and diagonal material should be coordinated [11]. The nodes of the main material can be arranged in unequal distance, and the intersection of the inclined material and the main material is staggered on the front and side of the tower, which can save the steel consumption on the premise of ensuring the safety and reliability of the tower structure.

\section{Cable design}

The cable laying route should be combined with the overall urban planning. The cable civil engineering facilities should be implemented simultaneously with the municipal construction when conditions permit, and should be completed at one time according to the longterm planning of the power grid, so as to reduce the impact of repeated construction on the surrounding environment.

The cable trench or tunnel shall be used for Incoming and outgoing lines of important substations, loop concentration area, 18 and above number of cables, or local power corridor tension. When the cable channel excavation is blocked, the trenchless dragging pipe or pipe jacking technology should be reasonably considered. When the cable line is buried in the urban green belt, the thickness of the covering soil should meet the requirements of restoring the green vegetation.

On the premise of meeting the requirements of production, transportation, construction and induced voltage, the cable reel length should be increased as much as possible to reduce the number of joints. The cross interconnection box and grounding box should be set close to the cable joint as far as possible to reduce the length of grounding wire and cross interconnection line. For $110 \mathrm{kV}$ and above power cables, polyethylene is preferred as outer sheath rather than PVC. Composite sleeve material shall be selected for outdoor cable terminals in densely populated areas or places with explosion-proof requirements.

For the cable line with long path, the cable metal sheath grounding system should select the equal cross interconnection grounding [12]. The phase sequence arrangement of double circuit cable should be optimized to reduce the circulating current and loss of outer sheath. At the same time, the cable line intelligent monitoring system should be actively applied, such as intelligent grounding box, fault monitoring device, optical fiber temperature measurement system, etc.

Considering the power grid planning, construction and operation requirements, the cross section of cable laying structure is optimized. The number of civil engineering pipe holes should be reserved properly to improve the utilization rate of the line corridor and reduce the land occupation.
When the cable is laid in the way of pipe laying, the environmental protection HPVC material with high strength and good durability should be selected as the pipe laying material.

When cables are laid in cable trench or cable tunnel, the stress-bearing steel bars of $400 \mathrm{MPa}$ and above are preferred. The clamp and protection tube of single core cable should be made of non ferromagnetic environmentfriendly renewable materials, which can effectively reduce the power loss.

The water pump with energy saving and noise reduction should be used in the cable tunnel to minimize the number of municipal interfaces. Energy saving inductors, electronic ballasts or light-emitting diodes should be used for lighting in tunnels, and the lamps should be controlled in different areas. The setting of cable tunnel entrance and vent should be coordinated with the surrounding environment.

\section{Conclusions}

This paper introduces the "green design" method from four aspects: electrical design of transmission line, design of tower foundation, structural design of tower body and cable design. It can not only effectively reduce the line corridor, save land resources, protect the natural environment, save the amount of engineering materials, but also steadily and orderly promote the high-quality construction of transmission projects.

By using the "green design" method in the transmission line, the amount of concrete can be reduced by about $42.42 \%$, and the amount of reinforcement can be reduced by about $25.74 \%$. In this way, the overall cost can be reduced by $38.90 \%$.

To sum up, the application of "green design" sustainable concept in transmission line can form the scientific management experience and technical achievements that can be popularized, which can be used for reference by the power industry. The next step is to carry out research on green construction and green handover of transmission line projects, and form a set of green construction guidelines for transmission lines.

\section{REFERENCES}

1. Sun Yuping. Application of green design concept in municipal bridge design[J]. Engineering and Construction. 2021,pp.239-240.

2. Lu Guodong. Research on route selection in power line design[J]. Practical Electronics. 2018(10),pp.8485 .

3. Tian Xiaoyan, Yu Jixing. Application of 3D digital topographic map in power engineering design[J]. Construction Materials \& Decoration. 2015(48) ),pp.240-241.

4. Zhao Peng, Zhu Jinsheng, Han Yanming. Protection distance of transmission line to passive interference of shortwave radio direction finding station[J]. Power System Technology. 2012,36(05) ,pp.22-28 
5. Wang Rusong, Li Jian, Liu Wenxun, Zhao Yuantai. Application of 3D digital design in transmission line engineering[J]. Smart Power. 2015,43(08) ,pp.25-29

6. Fan Liang, Tang Jian. Status and Prospect of 3D modeling methods for overhead transmission lines $[\mathrm{J}]$. Southern Energy Construction. 2017,4(02) ,pp.120125.

7. Ma Ye, Gong Jiangang, Guo Jie, Fang Yuqun, Chen Shu. Comparison of induced electric quantity of $500 \mathrm{kV}$ overhead ground wire with different grounding methods. [J]. High Voltage Apparatus. 2016,52(05),pp.176-180.

8. Zhang Jihao. Application of energy saving and consumption reduction technology measures in power transmission and distribution lines[J]. Telecom World. 2019,26(10) ,pp.215-216.

9. Li Chao. Management and control of whole process mechanized construction of transmission line $[\mathrm{J}]$. Management \& Technology of SME. 2020(11) ,pp.15-16.

10. Qin Qingzhi, Yu Hong, Zhang Yiguo, Yan Tao, Lu Xianlong. Design and experimental study on unequal height foundation of transmission line $[\mathrm{J}]$. Electric Power Construction. 2008,29(12),pp.26-30.

11. Wu Dongqi. Optimal design of transmission line tower structure[J]. Mechanical and Electrical Information. 2015(03),pp.133-134.

12. Ye Guowen. Grounding system of $110 \mathrm{kV}$ and above high voltage cable line[J]. Guangdong Science \& Technology. 2010,19(16) ,pp.84-86. 